\title{
Critical appraisal of the long-term impact of memantine in treatment of moderate to severe Alzheimer's disease
}

This article was published in the following Dove Press journal:

Neuropsychiatric Disease and Treatment

28 October 2009

Number of times this article has been viewed

\author{
Umamon Puangthong \\ Ging-Yuek Robin Hsiung \\ Division of Neurology, Department \\ of Medicine, University of British \\ Columbia, Vancouver, BC, Canada
}

\begin{abstract}
Alzheimer's disease is the most common cause of dementia in older adults. The clinical features include progressive memory decline as well as cognitive deficits with executive dysfunction, language, visual perceptual difficulties, apraxia and agnosia. During the moderate to severe stage of the disease, there is a major decline in memory and function, while neuropsychiatric disturbances often emerge and patients become difficult to manage. These distressing symptoms increase caregiver burden and add to the direct costs of care of the patients. Any improvements in patient function and behavioral symptoms can reduce caregiver burden. Memantine has been available for a number of years in Europe and in North America. In this article, we examine the pharmacological rationale for its use, and the current clinical evidence for its efficacy and long-term effectiveness in the management of cognitive and behavioral symptoms in moderate to severe stages of Alzheimer's disease.
\end{abstract}

Keywords: memantine, Alzheimer's disease, dementia

\section{Introduction}

Alzheimer's disease (AD) is an incurable neurodegenerative disorder and the most common cause of dementia in older adults. In the Canadian Study of Health and Aging (CSHA), it was estimated that AD accounted for $75 \%$ of all dementias. ${ }^{1}$ The clinical features include progressive and relentless decline in memory and other cognitive spheres such as executive dysfunction, language problems, visual perceptual difficulties, apraxia and agnosia, as well as neuropsychiatric disturbances. ${ }^{2}$ During the moderate to severe stage of $\mathrm{AD}$, major decline in memory, function and behavior become evident. In turn, patients at this stage often become an enormous burden on caregivers, as well as a huge strain on the cost of health care for the society. Any improvements in patient function and relief from caregiver burden will significantly affect the health and well-being of both the patients and their family.

The pathological hallmarks of $\mathrm{AD}$ are the presence of neuritic plaques and neurofibrillary tangles. The composition of the senile plaques include amyloid beta peptide $(\mathrm{A} \beta)$, apolipoprotein $\mathrm{E}, \alpha_{1}$-antichymotrypsin, sulfated glycosaminoglycans, and complement factors, while the mature plaques may also contain ubiquitin, phosphorylated tau, and chromogranin-A., ${ }^{3,4}$ A number of molecular, genetic, and clinical studies suggest that $A \beta$ oligomers from amyloid precursor protein is the pivotal initiation step in $\mathrm{AD}$ pathogenesis, and is responsible for synaptic impairment in neuronal degenaration. ${ }^{5}$ Based on the amyloid cascade hypothesis, the formation of $\mathrm{A} \beta$ oligomers can interfere directly with memory formation, and trigger a host of secondary
Correspondence: Ging-Yuek Robin Hsiung Assistant Professor, Division of Neurology, Department of Medicine, University of British Columbia, S162 - 22II Wesbrook Mall, Koerner Pavillion, Vancouver, BC, Canada V6T 2B5 Email hsiung@interchange.ubc.ca 
processes including tau hyperphosphorylation, neurofibrillary tangles formation, synaptic degradation, excitotoxicity, oxidative injury, inflammation, demyelination, and eventual neuronal cell death. ${ }^{4}$ While the accumulation of amyloid is felt to be the main inciting factor of $\mathrm{AD}$ pathogenesis, the correlation between the formation and disposition of neuritic plaques and the clinical presentation of cognitive impairment remains unclear. ${ }^{6}$

As the disease progress, cholinergic and glutamateric neurotransmission decline. The currently approved AD treatments are aimed at improving neurotransmission in the remaining neurons, which include the cholinesterase inhibitors (ChEIs) and an N-methyl-D-aspartate (NMDA) antagonist, memantine. In this article, we examine the current evidence on efficacy of memantine and evaluate its impact on the long-term treatment in moderate to severe AD.

\section{Methods}

A literature review was performed by PubMed and EMBASE databases search. The following search terms were used in combination: Alzheimer's disease, moderate to severe, and randomized, controlled, trials, and RCT (accessed June 2009). Four RCTs examining the effects of memantine in moderate to severe $\mathrm{AD}$ were identified. While no RCT was longer than 28 weeks in duration, one had a follow-up extension phase for up to 52 weeks. A number of post-hoc analyses of the clinical trials have also been published. The results of these studies are summarized in Table 1. In addition, we examined the findings from a clinical effectiveness observational study with a mean follow-up duration of 30 months. We also reviewed the mechanism of action of memantine on $\mathrm{AD}$ and its clinical pharmacokinetic properties in human studies.

\section{Mechanism of action}

The rationale for memantine's use in treatment of $\mathrm{AD}$ is based on the glutamate hypothesis. ${ }^{7,8}$ Glutamate is one of the main excitatory neurotransmitters in the central nervous system (CNS) and is involved in memory and learning. ${ }^{9}$ Glutamate actions are counterbalanced by gamma-amino-butyric acid (GABA) which is the major inhibitory neurotransmitter in the CNS. It is hypothesized that high concentrations of glutamate cause an excess calcium influx through the ion channel that leads to excitotoxicity. ${ }^{10}$ It has been shown in $\mathrm{AD}$ patients that glutamate transporters in glial cells are reduced, while the presence of beta amyloid indirectly stimulates excessive glutamate production. ${ }^{11}$ This phenomenon is thought to contribute to the neurotoxicity of beta amyloid and eventual neuronal cell death in $\mathrm{AD} .{ }^{12}$ The excitotoxicity is mediated through N-methyl-D-aspartate (NMDA) receptors via increased selective permeability to calcium.

Memantine is a low to moderate affinity, uncompetitive NMDA receptor antagonist as well as a partial agonist of the NMDA receptor, which blocks the NMDA receptor channel in a use-dependent fashion. At lower concentration, memantine continues to allow the physiological synaptic signal to be recognized, while at a higher concentration, it blocks the pathological effect of excessive glutaminergic stimulation. This dual mechanism may allow memantine to act as a neuroprotective agent against excitotoxicity as well as an enhancer of synaptic integrity. ${ }^{9}$ Moreover, recent studies on animal models suggest that NMDA receptor induced neurotoxicity may be linked to neurofibrillary tangle mediated degeneration in $\mathrm{AD} \cdot{ }^{13}$ In addition, since $\mathrm{A} \beta$ deposits can act as an inflammatory stimulus to activate glial cells to release cytokines and trigger a cascade of toxic processes and resultant overactivation of NMDA receptors, inhibition of excessive glutaminergic excitation by memantine may also delay disease progression by inhibiting the inflammatory cascade. ${ }^{14-16}$ Recent studies in mice suggest that minimizing NMDA receptor activation during the early stages of chronic neuroinflammation can reduce glial cells activation and improve spatial memory deficits. ${ }^{17}$ These preclinical studies suggest that treatment with NMDA receptor antagonist may, in part, diminish cognitive decline by limiting neuroinflammation.

Memantine is currently the only NMDA receptor antagonist that is well tolerated in human clinical studies, and has been approved by the European Agency for the Evaluation of Medicinal Products (EMEA) and the US Food and Drug Administration (FDA) for treatment of moderate to severe $\mathrm{AD}$.

\section{Pharmacokinetics of memantine}

Memantine is well absorbed by oral administration. Peak plasma concentration is reached between 3 and 7 hours, with a low plasma protein binding fraction (45\%). Food has no effect on its absorption. ${ }^{18}$ Memantine has a linear pharmacokinetic pattern which can be achieved in approximately 3 weeks. The majority of ingested memantine is excreted via urine in unchanged form, with the reminder converted to 6-hydroxy-memantine, 1-nitroso-deaminated memantine and memantine $\mathrm{N}$-glucuronide conjugate. These polarized metabolites have no significant clinical effects. The hepatic microsomal cytochrome P450 system, including CYP2A6, CYP2C9, CYP2D6, CYP2E1, CYP3A, and CYP1A2, have no significant role in the metabolism of memantine. ${ }^{19}$ 
Table I Results of randomized controlled trials in moderate to severe Alzheimer's disease

\begin{tabular}{|c|c|c|c|c|c|c|}
\hline Study & $\begin{array}{l}\text { Number } \\
\text { of patients } \\
\text { (treatment/ } \\
\text { placebo) }\end{array}$ & $\begin{array}{l}\text { Mean } \\
\text { MMSE } \\
\text { at baseline }\end{array}$ & Follow-up & $\begin{array}{l}\text { Outcomes } \\
\text { measures }\end{array}$ & Main conclusion & References \\
\hline $\begin{array}{l}\text { MEM-MD-0I } \\
\text { (memantine vs placebo) }\end{array}$ & $178 / 172$ & 10 & 24 wks & $\begin{array}{l}\text { SIB, NPI, ADCS- } \\
\text { ADLsev CIBIC+, } \\
\text { BGP BGP-care, FAST }\end{array}$ & $\begin{array}{l}\text { Significant advantage with } \\
\text { Memantine on the SIB and } \\
\text { CIBIC+ at I } 2 \text { and I } 8 \text { weeks, } \\
\text { but no significant difference } \\
\text { at } 24 \text { wks }\end{array}$ & $\begin{array}{l}\text { van Dyck } \\
\text { et } \mathrm{al}^{24}\end{array}$ \\
\hline $\begin{array}{l}\text { MEM-MD-02 (memantine plus } \\
\text { donepezil vs placebo plus } \\
\text { donepezil) }\end{array}$ & $203 / 201$ & 10 & 24 wks & $\begin{array}{l}\text { ACDS-ADLsev } \\
\text { CIBIC+, SIB, NPI, } \\
\text { BGP-care }\end{array}$ & $\begin{array}{l}\text { Memantine plus donepezil } \\
\text { showed significant benefits } \\
\text { in all measures compared to } \\
\text { placebo plus donepezil }\end{array}$ & Tariot et $\mathrm{a}^{23}$ \\
\hline \multicolumn{3}{|c|}{ Post-hoc analysis of responders: MEM-MD-02 } & & $\begin{array}{l}\text { ACDS-ADLsev } \\
\text { CIBIC+, SIB, NPI }\end{array}$ & $\begin{array}{l}\text { Responder analyses show an } \\
\text { NNT of } 8-10 \text {, and memantine } \\
\text { produces both clinically } \\
\text { important improvement and } \\
\text { stabilization of symptoms }\end{array}$ & $\begin{array}{l}\text { van Dyck } \\
\text { et } \mathrm{al}^{4 !}\end{array}$ \\
\hline Post-hoc analysis of cognitive ef & fects: MEM-MD- & & & SIB & $\begin{array}{l}\text { Beneficial cognitive effects on } \\
\text { memory, language, and praxis } \\
\text { with memantine treatment }\end{array}$ & Schmitt et $\mathrm{al}^{42}$ \\
\hline Post-hoc analysis of behavioral $e$ & effects: MEM-MD & & & NPI & $\begin{array}{l}\text { Memantine reduced agitation/ } \\
\text { aggression, irritability, and } \\
\text { appetite/eating disturbances }\end{array}$ & $\begin{array}{l}\text { Cummings } \\
\text { et } \mathrm{al}^{43}\end{array}$ \\
\hline Post-hoc analysis of functional $\circ$ & utcome: MEM-N & ID-02 & & ADCS-ADL & $\begin{array}{l}\text { Memantine showed benefits } \\
\text { on function with grooming, } \\
\text { toileting, conversing, watching } \\
\text { TV, and being left alone }\end{array}$ & $\begin{array}{l}\text { Feldman } \\
\text { et } \mathrm{al}^{44}\end{array}$ \\
\hline Memantine vs placebo & $126 / 126$ & 8 & 28 wks & $\begin{array}{l}\text { ACDS-ADLsev } \\
\text { CIBIC+, SIB, NPI, } \\
\text { MMSE, FAST, GDS }\end{array}$ & $\begin{array}{l}\text { Memantine had better } \\
\text { outcome on ACDS-ADL, } \\
\text { CIBIC+ and SIB }\end{array}$ & $\begin{array}{l}\text { Reisberg } \\
\text { et } \mathrm{al}^{22}\end{array}$ \\
\hline $\begin{array}{l}\text { 24-wk open-label extension } \\
\text { of the } 28 \text {-wk RCT }\end{array}$ & & & 52 wks & $\begin{array}{l}\text { ACDS-ADLsev } \\
\text { CIBIC+, SIB, NPI, } \\
\text { MMSE, FAST, GDS }\end{array}$ & $\begin{array}{l}\text { Patients who switched from } \\
\text { placebo to memantine had } \\
\text { improvements in all efficacy } \\
\text { measures (relative to rate of } \\
\text { decline in placebo phase) }\end{array}$ & $\begin{array}{l}\text { Reisberg } \\
\text { et } \mathrm{al}^{36}\end{array}$ \\
\hline $\begin{array}{l}\text { Post-hoc analysis of functional } \\
\text { disability in the } 28 \text {-wk RCT }\end{array}$ & & & 28 wks & ACDS-ADLsev & $\begin{array}{l}\text { Memantine-treated patients } \\
\text { were } 3 \text { times more likely to } \\
\text { remain autonomous }\end{array}$ & Rive et $\mathrm{al}^{40}$ \\
\hline $\begin{array}{l}\text { Post-hoc health economic } \\
\text { analysis of the } 28 \text { wk RCT }\end{array}$ & & & 28 wks & RUD & $\begin{array}{l}\text { Resource utilization and total } \\
\text { health costs were lower in } \\
\text { the memantine treated group }\end{array}$ & Wimo et $\mathrm{al}^{39}$ \\
\hline $\begin{array}{l}\text { 9M-Best study } \\
\text { (memantine vs placebo) }\end{array}$ & $82 / 84$ & 6 & 12 wks & $\begin{array}{l}\text { CGI-C, BPG, } \\
\text { BPG-care, Ferm's } \\
\text { D-scale }\end{array}$ & $\begin{array}{l}\text { Significant improvement in } \\
\mathrm{CGI}-\mathrm{C} \text { and BPG favoring } \\
\text { memantine treatment }\end{array}$ & $\begin{array}{l}\text { Winblad and } \\
\text { Poritis }^{21}\end{array}$ \\
\hline
\end{tabular}

Abbreviations: ADCS-ADLsev, Alzheimer's Disease cooperative Study Activities of Daily Living Scale - a modified version for severe AD patients; BGP (BPG-care), Behavior Rating Scale for Geriatric Patients (BPG-care = BPG-care dependency subscale); CGI-C, Clinical Global Impression-change; CIBIC+, Clinician's Interview Based Impression of Change with caregiver input; FAST, Functional Assessment Staging Tool; GDS, Global Deterioration Scale; MMSE, Mini Mental State Examination; NPI, Neuropsychiatric Inventory; RUD, Resource Utilization in Dementia scale; SIB, severe impairment battery.

The combination of donepezil and memantine does not alter its pharmacokinetics nor pharmacodynamics. ${ }^{20}$ No dosage adjustment is needed in patients with mild to moderate hepatic impairment, but caution is recommended in severe hepatic impairment since no data on its pharmacokinetics have been reported. The recommended starting dose of memantine is $5 \mathrm{mg}$ daily. The dose can be increased gradually to $10 \mathrm{mg}$ twice daily by adding $5 \mathrm{mg}$ per week. ${ }^{2}$ No dosage 
adjustment is needed in patients with mild to moderate renal impairment; however, a decreased dosage to $10 \mathrm{mg}$ once daily is recommended in patients with severe renal impairment. ${ }^{19}$

\section{Randomized control trials of memantine in moderate to severe AD}

Four double-blind randomized controlled trials (RCT) of memantine in patients with moderate to severe AD were retrieved from PubMed search (last accessed 8 June 2009). ${ }^{21-24}$ The findings of the RCTs are summarized in Table 1. The first RCT, 9M-BEST (Benefit and Efficacy in Severely Demented Patients during Treatment with Memantine) study, was a multicenter study conducted in Latvia. ${ }^{21}$ One hundred and sixty-six patients were randomized to receive either memantine $10 \mathrm{mg}$ per day or placebo for 12 weeks. It included patients with $\mathrm{AD}$ and vascular dementia with an age range between 60 to 80 years. Dementia was diagnosed by DSM-III-R criteria. ${ }^{25}$ Other inclusion criteria included Mini-Mental State Examination (MMSE) score of $<10$ (average $=6$ ), Global Deterioration Scale (GDS) stages between 5 and 7 , and a duration of dementia of at least 12 months. ${ }^{26}$ The primary end points were the Clinical Global Impression of Change (CGI-C) rated by clinicians, and the care dependency subscale of the Behavioral Rating Scale for Geriatric Patients (BGP) rated by nursing staff. Secondary end points included the Ferm's D-test, the Clinical Global Impression of severity of illness (CGI-S), and the BGP total score. ${ }^{27} \mathrm{~A}$ significantly greater percentage of patients was improved on CGI-C in the memantine group compared to placebo ( $73 \%$ vs $42 \%, P<0.001)$. There was also significant benefit with memantine on the BPG care dependency subscale. Secondary end point analysis of CGI-S results were also superior in the memantine group ( $78 \%$ vs $53 \% P=0.016$ ), and significant behavioral improvements were demonstrated on every item of the Ferm's D-test.

In a longer-term study, Reisberg et al reported the results of a 28-week, double-blind, multicenter RCT conducted in the US. ${ }^{22}$ Two hundred and fifty-two patients with moderate to severe AD by DSM-IV criteria were randomized to receive memantine versus placebo. ${ }^{28}$ Inclusion criteria included an MMSE score of 3 to 14, GDS stage of 5 or 6 , and a stage of $6 \mathrm{a}$ or higher on the Functional Assessment Staging instrument (FAST) ${ }^{29}$ The primary outcome measures were the Clinician's Interview-Based Impression of Change Plus Caregiver Input (CIBIC-Plus) at 28 weeks, and the Alzheimer's disease Cooperative Study Activities of
Daily Living Inventory modified for more severe dementia (ADCS-ADLsev). ${ }^{30-32}$ Using an intention-to-treat analysis (ITT) with last observation carried forward (LOCF), a trend favoring memantine treated patients $(P=0.06)$ was shown in the CIBIC-Plus, while analysis based on observed cases demonstrated statistically significant benefits $(P=0.03)$. The ADCS-ADLsev also showed significantly better scores with memantine $(P=0.02)$. Secondary outcome measures in this study included the Severe Impairment Battery (SIB), MMSE, GDS, FAST, the Neuropsychiatric Inventory (NPI), and the Resource Utilization in Dementia (RUSP). ${ }^{33-35}$ Memantine-treated patients had significant better scores than placebo on the SIB $(P=0.002)$ as well as the FAST $(P=0.007)$. However, there were no statistically significant differences on the secondary measures of MMSE, GDS, and NPI. In the RUSP analysis, caregivers were able to spend 45.8 hours per month less when caring for patients receiving memantine compared to placebo $(P=0.01)$. This 28 -week RCT was followed by a 24 -week open-label extension phase. ${ }^{36}$ When the 80 patients who were initially treated with placebo received memantine $20 \mathrm{mg}$ daily during this 24 -week extension, they had a significantly slower rate of decline on the CIBIC-Plus $(P<0.01)$, ADCS-ADL $(P=0.021)$, and the $\operatorname{SIB}(P=0.049)$. Limitations of this study include a high exclusion rate $(27 \%)$ and a high dropout rate $(28 \%)$, which raises questions on the generalizability of the results and the clinical relevance of the relatively small, although statistically significant, improvements in the outcome measures. ${ }^{37,38}$

Two post-hoc analyses were derived from this study. In a cost analysis by Wimo et al, it was demonstrated that resource utilization and total health costs were lower in the memantine-treated group compared to placebo. ${ }^{39}$ Further analysis of resource utilization showed that caregiver time for patients receiving memantine was significantly less than those receiving placebo (difference of 51.52 hours per month; 95\% CI -95.27, -7.17). An analysis of total caregiver costs and total societal costs also favored memantine. Another post-hoc analysis by Rive et al focused on activities of daily living. ${ }^{40}$ It was found that patients treated with memantine were three times more likely (odds ratio $[\mathrm{OR}]=3.03 ; 95 \%$ confidence interval $[\mathrm{CI}]=1.38,6.66$ ) to remain autonomous after 6 months than those on placebo.

In the third RCT reported by Tariot et al (MEM-MD-02), the effectiveness of augmentation therapy with memantine combined with donepezil was examined ${ }^{23}$ Four hundred and four patients with a diagnosis of moderate to severe $\mathrm{AD}$ (based on the National Institute of Neurological and Communicative Disorders and Stroke - Alzheimer Disease and Related 
Disorders Association criteria (NINCDS-ADRDA)) who had been stable on donepezil for at least 6 months with an MMSE score of 5 to 14 were randomized to receive memantine with donepezil versus placebo with donepezil for 24 weeks. The primary outcome measures were the change on the SIB and the ADCS-ADLsev. There was a statistically significant benefit of memantine treatment on the SIB $(P=0.01)$ as well as ADCS-ADLsev $(P=0.03)$. All of the secondary measures with CIBIC-Plus, NPI, and BPG also demonstrated significant benefits for the memantine group compared to placebo, with either observed cases only or LOCF analysis.

A number of post-hoc analyses were derived from this study. In a subgroup analysis by Van Dyck et al, using several different sets of criteria as "responders", it was found that there is clinically significant stabilization of symptoms in the memantine treated group on the SIB $(P=0.0443)$, ADCS-ADL $(P=0.0318)$, CIBIC-Plus $(P=0.0223)$, and NPI $(P=0.0129)$ with 6 out of 10 definitions of "responders". ${ }^{41}$ The number needed to treat (NNT) was estimated to be 8 to 10 . The second post-hoc analysis was a re-analysis of the cognitive response of the SIB to memantine over the 24-week period by both observed cases and LOCF approaches. ${ }^{42}$ The effect of memantine on the individual items of SIB, subscale performance and 3 post-hoc-derived aggregate subscales were investigated. It was shown that there is significantly greater improvement on memory, language, and praxis. In another post-hoc analysis on the behavioral effects of memantine using the NPI, it was found that the total NPI score was significantly increased in the placebo group at week 12 and continued to worsen at week 24, whereas NPI scores declined in the memantine-treated group at week 12 and returned to baseline at week $24 .{ }^{43}$ Analyses by using both LOCF or observed cases produced similar conclusion. Analyses of the 12 NPI domains showed significant differences in favor of memantine on agitation/aggression, irritability/lability and eating/appetite. In the final posthoc analysis on activities of daily living using the 19-item Alzheimer's Disease Cooperative Study - Activities of Daily Living Inventory (ADCS-ADL-19), it was found that memantine-treated patients had significantly less decline in total ADCS-ADL-19 scores compared with placebo. ${ }^{44}$ Specific item analysis showed benefits with memantine on grooming, toileting, making conversation, watching television, and being left alone.

In the most recently published 24-week RCT study (MEMMD-01) examining the efficacy and safety of memantine monotherapy in moderate to severe $\mathrm{AD}, 350$ patients with probable AD by NINCDS-ADRDA diagnostic criteria were randomized to receive memantine $\left(20 \mathrm{mg}\right.$ /day) or placebo. ${ }^{24}$ The entry MMSE score range was 5 to 14 . The presence of other psychiatric or neurologic disorders, or a Hachinski Ischemia Score (HIS) of greater than 4 were excluded. ${ }^{45}$ Patients were not allowed to receive ChEI therapy within a month. The primary outcome measures were changes on the SIB and ADCS-ADL-19 from baseline to week 24. Secondary outcome measures included the CIBIC-Plus, NPI, FAST, and BGP. Prospectively defined analyses failed to reveal any significant benefit of memantine on the SIB or CIBIC-Plus, although a significant advantage was observed for memantine at weeks 12 and 18 with both outcome measures. None of the secondary measures demonstrated any significant difference between memantine and placebo.

\section{Observational study of long-term effectiveness of memantine}

In a clinical effectiveness observational study comparing combination therapy (memantine plus a ChEI), ChEI alone, and no treatment with a mean observational period of 30 months (mean cumulative medication treatment = 22.5 months), it was found that the group receiving combination therapy had significantly lower mean annualized rates of deterioration on the Blessed Dementia Scale (BDS) and the Weintraub Activities of Daily Living (ADL) scores compared with ChEI alone $(P<0.001$; Cohen's dBDS $=0.10-0.34$ and $\mathrm{dADL}=0.23-0.46$ at 1 to 2 years) and the no-treatment group $(P<0.001$; Cohen's dBDS $=0.56-0.73$ and $\mathrm{dADL}=0.32-0.48$ at 1 to 2 years). ${ }^{46-48}$ For the combination therapy group, Cohen's d effect sizes was greater with increasing treatment duration. Similar comparisons also significantly favored the ChEI group over the no-treatment group on the BDS. The authors concluded that combination therapy may be more effective at slowing cognitive and functional decline in $\mathrm{AD}$ compared with ChEI monotherapy and no treatment.

\section{Safety and tolerability}

Memantine is generally well tolerated. While the frequency of adverse events was high in the 4 RCTs, there were no significant differences between memantine treatment and placebo in the number of patients suffering least 1 adverse event. Agitation occurred less commonly as an adverse event in all studies in those taking memantine compared to those taking placebo ( $\mathrm{OR}=0.6,95 \% \mathrm{CI} 0.42$ to $0.86, P=0.005$ ). There were no other consistent differences in specific adverse events between memantine and placebo. ${ }^{21,22}$ Discontinuations due to adverse events were fewer in the memantine groups 
than in placebos $(7.4 \%$ vs $12.4 \%) .{ }^{23}$ Furthermore, incidence of gastrointestinal adverse events was lower in the memantine plus donepezil group compared with the placebo plus donepezil group. This result led to the speculation that memantine treatment may ameliorate some of the gastrointestinal adverse effects associated with ChEIs. ${ }^{23}$

In an analysis of the pooled data for tolerability and safety from 6 double-blind RCTs ( 3 in mild to moderate AD and 3 in moderate to severe $\mathrm{AD}$ ) and 4 open-label extensions period of those studies ( 2 in mild to moderate AD and 2 in moderate to severe AD), it was found that the safety and tolerability profile of memantine was more favorable compared to placebo group. ${ }^{49}$ The adverse events most often reported in both placebo-treated and memantine-treated patients included agitation (12\% vs $7.5 \%$, respectively), falls $(7.1 \%$ vs $6.8 \%)$, dizziness (5.7\% vs 6.3\%), accidental injury $(7.2 \%$ vs $6 \%)$, influenza-like symptoms ( $5.8 \%$ vs $6 \%)$, headache $(3.7 \%$ vs $5.2 \%)$, and diarrhea (5.6\% vs $5 \%$ ).

In a study of 3 different dosing schedules of memantine (i. $20 \mathrm{mg}$ once daily with a 1-step up-titration, ii. $20 \mathrm{mg}$ once daily with a 3-step up-titration, and iii. $10 \mathrm{mg}$ twice daily with a 3-step up-titration) in a 12-week RCT study of 78 patients with moderate to severe AD, it was found that once-daily dosing and twice-daily dosing of memantine are similar in terms of safety and tolerability.$^{50}$ Despite the relatively small number of subjects in each group, the number of withdrawals due to adverse events was low, and the adverse event were only mild to moderate.

The tolerability of switching from a ChEI to memantine has been evaluated in a study with an 8-week follow-up period in 46 moderate to severe AD patients switching from stable donepezil to memantine. ${ }^{51}$ The study concluded memantine was well tolerated, with a similar adverse event profile regardless of whether donepezil was discontinue abruptly or stepwise (decrease of $5 \mathrm{mg} /$ day donepezil over 2 weeks).

\section{Behavioral and psychological effects of memantine}

Several studies have examined the behavioral and psychological benefits of memantine. ${ }^{43,52-56}$ However, these studies used data collected from previously reported clinical trials, and therefore are not independent from each other. Gauthier et al investigated the effect of memantine on the behavioral symptoms in AD in a pooled analysis of 6 RCTs. ${ }^{52}$ The outcome was based on NPI scores, which were defined by 2 categories: (1) symptom improvement: assessed in patients who displayed the symptom at baseline, and (2) symptom emergence: assessed in patients who did not have the symptom at base- line. The pooled study population from the $6 \mathrm{RCTs}$ consists of 2311 patients (1242 patients were memantine-treated and 1069 patients were placebo-treated). ${ }^{22-24,57-59}$ The mean baseline MMSE was 12. The result showed significant improvements in total NPI scores in memantine-treated patients compared to placebo with LOCF analyses at week 12 $(P=0.001)$ and week $24 / 28(P=0.008)$. In the single NPI item analyses, there were significant benefits with memantine on symptoms of delusion $(P=0.07$ at week $12, P=0.01$ at week 24/28), hallucinations ( $P=0.037$ at week 12 , number not reported at week $24 / 28)$, agitation/aggression $(P=0.001$ at week $12, P=0.001$ at week $24 / 28)$, and irritability/lability $(P=0.005$ at week 24/28). Analysis of symptom emergence also indicated that memantine-treated patients had a lower incidence of agitation/aggression $(P=0.002)$, delusion $(P=0.047)$, and disinhibition $(P=0.011)$ at week 12 and of agitation/aggression $(P=0.002)$, irritability/lability $(P=0.004)$ and night-time behavior $(P=0.05)$ at week $24 / 28$. The results of the analysis of only observed cases produced similar findings.

Maidment et al performed a meta-analysis of NPI scores from 5 RCT studies. ${ }^{54}$ The pooled study population included a total of 1750 patients, with 868 patients treated with memantine and 882 patients treated with placebo. ${ }^{22-24,57,58}$ Memantine was significnantly better than placebo on NPI outcome in 2 studies. ${ }^{23,57}$ The NPI change score non-significantly favored memantine in another 2 RCTs, and non-significantly favored placebo in a 1 trial. ${ }^{22,24,58}$ Using a random effects model, it was concluded that memantine significantly reduced the total mean NPI score $(-1.99 ; 95 \% \mathrm{CI}-0.08$ to $-3.91 ; P=0.041)$, although the effect size was relatively small.

Wilcock et al performed another pooled analysis of memantine on moderate to severe AD to evaluate the effects of memantine on the behaviorally disturbed population (BDP). ${ }^{53}$ A total of 593 patients (306 patients receiving memantine and 287 patients receiving placebo) from thre RCTs were analyzed. ${ }^{22-24}$ The BDP was defined as any patient who had symptoms on any of the 3 NPI items of agitation/ aggression, delusions, or hallucinations at baseline. The results revealed a significant benefit for memantine compared to placebo on the NPI cluster (agitation/aggression, delusions and hallucinations) score at both week $12(\mathrm{p}=0.0014)$ and week $24 / 28(P=0.0004)$. In addition, placebo-treated patients in this population demonstrated an accelerated disease progression for global (CIBIC-Plus Caregiver Input), cognitive (SIB), and functional (ADCS-ADL-19) outcomes compared to memantine-treated patients. However, in a secondary analysis of the 3 individual NPI items, only the 
item of agitation/aggression demonstrated a significant improvement in patients receiving memantine compared with those receiving placebo at week 12 (55.3\% vs 43.1\%; $P=0.011)$ and week $24 / 28(61 \%$ vs $45 \% ; p<0.001)$. In patients who were asymptomatic at baseline, significantly fewer memantine treated patients went on to develop these symptoms at week $12(20.3 \%$ vs $31.9 \% ; P=0.10)$ and week $24 / 28(24.2 \%$ vs $37 \% ; P=0.007)$.

A recent study from the French national healthcare database examined the use of psychotropic medications before and after the initiation of memantine of 4600 patients. $^{60}$ Prior to initiation of memantine, there was a trend for increasing psychotropic drug use as the disease progress. However, after initiation of memantine, the proportion of psychotropic drug use remained stable. This change in the trend was statistically significantly $(P<0.001)$.

\section{Discussion}

Based on the current evidence, memantine treatment diminishes the rate of cognitive decline in patients with moderate to severe AD and is well tolerated. Furthermore, memantine treatment showed significant benefits in reducing behavioral disturbances on agitation/aggression as well as minimizing concomitant psychotropics use. ${ }^{53,56,60}$ Combination therapy with another ChEI may be more efficacious in slowing cognitive and functional decline than ChEI monotherapy. ${ }^{23,46,61,62}$ Most RCTs of memantine in moderate to severe $\mathrm{AD}$ patients to date have demonstrated benefits in improving or stabilizing cognitive outcomes demonstrated in the SIB and CIBIC+, although functional outcomes measures are more variable. ${ }^{63}$ However, at least one study failed to show any sustained effects for the duration of the follow-up period. ${ }^{24}$

Despite the RCT evidence of efficacy of memantine, it remains difficult to translate significant differences on research measures into clinically relevant differences for patients and their families. A numeric change on cognitive measures may not fully reflect the impact on functioning of the patients. More sensitive instruments to assess clinically meaningful improvements in dementia treatments are being developed. ${ }^{64-67}$ Further education for the public on translation of research findings and implications of clinical studies may also improve understanding and public acceptance.

Many studies have been devoted to cost-effectiveness. A study in Canada by Gagnon et al evaluated the cost-effectiveness of memantine compared with standard care (without ChEIs) in moderate to severe AD. ${ }^{68}$ It was found that memantine monotherapy saved more than a month of complete dependence and produced 0.03 additional quality-adjusted life years (QALYs), with no additional cost. Results are consistent with those of other economic evaluations of memantine performed in the US and Europe..$^{39,69-72}$ However, these studies employed different methods to determine the potential value of treatment, and there is still a lack of consensus on how to measure quality of life among demented people and their caregivers. Some have even argued that using QALY-based measurements may not be appropriate for people with dementia. ${ }^{73}$ Furthermore, most of the currently reported RCTs are short term, with the longest study lasting only up to 28 weeks; thus the true longterm efficacy of memantine for a slowly progressive disease such as AD remains to be confirmed. On the other hand, the safety and tolerability profile of memantine in clinical use has been excellent, with relatively few adverse events. ${ }^{49}$ There are no significant interactions with drugs metabolized by cytochrome P450. For patients who experienced adverse effects or could not tolerate any ChEIs, memantine monotherapy can be an option and may still offer some benefits.

In conclusion, memantine is currently the only agent approved for treatment in patients with moderate to severe AD. It can be used as a monotherapy or in combination with other ChEIs. There are consistent clinical benefits demonstrated on cognition, global functioning, and neurobehavioral symptoms. In earlier stages of $\mathrm{AD}$, however, the effect of memantine is unclear. Moreover, there is uncertainty about the most appropriate time to discontinue treatment. When evaluating treatment response of memantine in a patient, it is also important to ask whether caregivers experienced any improvement in their own quality of life or their stress. More studies with longer duration of treatment and more transparent economic analyses will be helpful in determining the long-term benefits of memantine in treatment of AD.

\section{Disclosures}

Dr Hsiung has participated as a site investigator in clinical trials supported by Bristol-Myers Squibb, Elan, Glaxo Smith Kline, Hoffmann-La Roche, and Pfizer.

\section{References}

1. Ebly EM, Parhad IM, Hogan DB, Fung TS. Prevalence and types of dementia in the very old: results from the Canadian Study of Health and Aging. Neurology. 1994;44:1593-1600.

2. Cummings JL. Alzheimer's disease. N Engl J Med. 2004;351:56-67.

3. Gotz J, Ittner LM, Schonrock N, Cappai R. An update on the toxicity of Abeta in Alzheimer's disease. Neuropsychiatr Dis Treat. 2008;4: 1033-1042.

4. Armstrong RA. Plaques and tangles and the pathogenesis of Alzheimer's disease. Folia Neuropathol. 2006;44:1-11. 
5. Walsh DM, Klyubin I, Fadeeva JV, Rowan MJ, Selkoe DJ. Amyloid-beta oligomers: their production, toxicity and therapeutic inhibition. Biochem Soc Trans. 2002;30:552-557.

6. Mackenzie IR. Senile plaques do not progressively accumulate with normal aging. Acta Neuropathol. 1994;87:520-525.

7. Olney JW, Wozniak DF, Farber NB. Excitotoxic neurodegeneration in Alzheimer disease. New hypothesis and new therapeutic strategies. Arch Neurol. 1997;54:1234-1240.

8. Molinuevo JL, Llado A, Rami L. Memantine: targeting glutamate excitotoxicity in Alzheimer's disease and other dementias. Am J Alzheimers Dis Other Demen. 2005;20:77-85.

9. Danysz W, Parsons CG. The NMDA receptor antagonist memantine as a symptomatological and neuroprotective treatment for Alzheimer's disease: preclinical evidence. Int J Geriatr Psychiatry. 2003;18: S23-S32.

10. Whetsell WOJ, Shapira NA. Neuroexcitation, excitotoxicity and human neurological disease. Lab Invest. 1993;68:372-387.

11. Hynd MR, Scott HL, Dodd PR. Glutamate-mediated excitotoxicity and neurodegeneration in Alzheimer's disease. Neurochem Int. 2004; 45:583-595.

12. Rammes G, Danysz W, Parsons CG. Pharmacodynamics of memantine: an update. Curr Neuropharmacol. 2008;6:55-78.

13. Chohan MO, Iqbal K. From tau to toxicity: emerging roles of NMDA receptor in Alzheimer's disease. J Alzheimers Dis. 2006;10:81-87.

14. Walton HS, Dodd PR. Glutamate-glutamine cycling in Alzheimer's disease. Neurochem Int. 2007;50:1052-1066.

15. Wenk GL, McGann-Gramling K, Hauss-Wegrzyniak B, et al. Attenuation of chronic neuroinflammation by a nitric oxide-releasing derivative of the antioxidant ferulic acid. J Neurochem. 2004;89:484-493.

16. Rosi S, Ramirez-Amaya V, Hauss-Wegrzyniak B, Wenk GL. Chronic brain inflammation leads to a decline in hippocampal NMDA-R1 receptors. J Neuroinflammation. 2004;1:12.

17. Rosi S, Vazdarjanova A, Ramirez-Amaya V, Worley PF, Barnes CA, Wenk GL. Memantine protects against LPS-induced neuroinflammation, restores behaviorally-induced gene expression and spatial learning in the rat. Neuroscience. 2006;142:1303-1315.

18. Parsons CG, Danysz W, Quack G. Memantine is a clinically well tolerated N-methyl-D-aspartate (NMDA) receptor antagonist - a review of preclinical data. Neuropharmacology. 1999;38:735-767.

19. Periclou A, Ventura D, Rao N, Abramowitz W. Pharmacokinetic study of memantine in healthy and renally impaired subjects. Clin Pharmacol Ther. 2006;79:134-143.

20. Periclou AP, Ventura D, Sherman T, Rao N, Abramowitz WT. Lack of pharmacokinetic or pharmacodynamic interaction between memantine and donepezil. Ann Pharmacother. 2004;38:1389-1394.

21. Winblad B, Poritis N. Memantine in severe dementia: results of the 9M-Best Study (Benefit and efficacy in severely demented patients during treatment with memantine). Int J Geriatr Psychiatry. 1999;14:135-146.

22. Reisberg B, Doody R, Stoffler A, Schmitt F, Ferris S, Mobius HJ. Memantine in moderate-to-severe Alzheimer's disease. $N$ Engl J Med. 2003;348:1333-1341

23. Tariot PN, Farlow MR, Grossberg GT, Graham SM, McDonald S, Gergel I. Memantine treatment in patients with moderate to severe Alzheimer disease already receiving donepezil: a randomized controlled trial. JAMA. 2004;291:317-324.

24. van Dyck CH, Tariot PN, Meyers B, Malca Resnick E. A 24-week randomized, controlled trial of memantine in patients with moderate-tosevere Alzheimer disease. Alzheimer Dis Assoc Disord. 2007;21:136-143.

25. American Psychiatric Association. Diagnostic and Statistical Manual of Mental Disorders, 3rd edition revised (DSM-III-R). Washington, DC, APA 1987.

26. Reisberg B, Ferris SH, de Leon MJ, Crook T. The Global Deterioration Scale for assessment of primary degenerative dementia. Am J Psychiatry. 1982;139:1136-1139.

27. Ferm L. Behavioural activities in demented geriatric patients. Study based on evaluations made by nursing staff members and on patients' scores on a simple psychometric test. Gerontol Clin (Basel). 1974;16:185-194.
28. American Psychiatric Association. Diagnostic and Statistical Manual of Mental Disorders, 4th edition (DSM-IV). Washington, DC, APA 1994.

29. Sclan SG, Reisberg B. Functional assessment staging (FAST) in Alzheimer's disease: reliability, validity, and ordinality. Int Psychogeriatr. 1992;4 Suppl 1:55-69.

30. Galasko D, Bennett D, Sano M, et al. An inventory to assess activities of daily living for clinical trials in Alzheimer's disease. The Alzheimer's Disease Cooperative Study. Alzheimer Dis Assoc Disord. 1997;11 Suppl 2: S33-S39.

31. Schneider LS, Olin JT, Doody RS, et al. Validity and reliability of the Alzheimer's Disease Cooperative Study-Clinical Global Impression of Change. The Alzheimer's Disease Cooperative Study. Alzheimer Dis Assoc Disord. 1997;11 Suppl 2:S22-S32.

32. Galasko DR SF, Jin S, et al. Detailed assessment of cognition and activities of daily living in moderate to severe Alzheimer's disease. [abstract]. Neurobiol Aging. 2000;21:S168.

33. Panisset M, Roudier M, Saxton J, Boller F. Severe impairment battery. A neuropsychological test for severely demented patients. Arch Neurol. 1994;51:41-45.

34. Schmitt FA, Ashford W, Ernesto C, et al. The severe impairment battery: concurrent validity and the assessment of longitudinal change in Alzheimer's disease. The Alzheimer's Disease Cooperative Study. Alzheimer Dis Assoc Disord. 1997;11 Supp1 2:S51-S56.

35. Cummings JL, Mega M, Gray K, Rosenberg-Thompson S, Carusi DA, Gornbein J. The Neuropsychiatric Inventory: comprehensive assessment of psychopathology in dementia. Neurology. 1994;44:2308-2314.

36. Reisberg B, Doody R, Stoffler A, Schmitt F, Ferris S, Mobius HJ. A 24-week open-label extension study of memantine in moderate to severe Alzheimer disease. Arch Neurol. 2006;63:49-54.

37. Kertesz A. Memantine in moderate to severe Alzheimer's disease. Curr Neurol Neurosci Rep. 2003;3:485-486.

38. Bleich S, Wiltfang J, Kornhuber J. Memantine in moderate-to-severe Alzheimer's disease. N Engl J Med. 2003;349:609-610; author reply 609-610.

39. Wimo A, Winblad B, Stoffler A, Wirth Y, Mobius HJ. Resource utilisation and cost analysis of memantine in patients with moderate to severe Alzheimer's disease. Pharmacoeconomics. 2003;21:327-340.

40. Rive B, Vercelletto M, Damier FD, Cochran J, Francois C. Memantine enhances autonomy in moderate to severe Alzheimer's disease. Int $J$ Geriatr Psychiatry. 2004;19:458-464.

41. van Dyck CH, Schmitt FA, Olin JT. A responder analysis of memantine treatment in patients with Alzheimer disease maintained on donepezil. Am J Geriatr Psychiatry. 2006;14:428-437.

42. Schmitt FA, van Dyck CH, Wichems CH, Olin JT. Cognitive response to memantine in moderate to severe Alzheimer disease patients already receiving donepezil: an exploratory reanalysis. Alzheimer Dis Assoc Disord. 2006;20:255-262.

43. Cummings JL, Schneider E, Tariot PN, Graham SM. Behavioral effects of memantine in Alzheimer disease patients receiving donepezil treatment. Neurology. 2006;67:57-63.

44. Feldman HH, Schmitt FA, Olin JT. Activities of daily living in moderateto-severe Alzheimer disease: an analysis of the treatment effects of memantine in patients receiving stable donepezil treatment. Alzheimer Dis Assoc Disord. 2006;20:263-268.

45. Rosen WG, Terry RD, Fuld PA, Katzman R, Peck A. Pathological verification of ischemic score in differentiation of dementias. Ann Neurol. 1980; 7:486-488.

46. Atri A, Shaughnessy LW, Locascio JJ, Growdon JH. Long-term course and effectiveness of combination therapy in Alzheimer disease. Alzheimer Dis Assoc Disord. 2008;22:209-221.

47. Blessed G, Tomlinson BE, Roth M. The association between quantitative measures of dementia and of senile change in the cerebral grey matter of elderly subjects. Br J Psychiatry. 1968;114:797-811.

48. S W. The record of independent daily living: an informant completed measure of activities of daily living and behavior in elderly patients with cognitive impairment. American Journal Alzheimer Care. 1986;1:35-39. 
49. Farlow MR, Graham SM, Alva G. Memantine for the treatment of Alzheimer's disease: tolerability and safety data from clinical trials. Drug Saf. 2008;31:577-585.

50. Jones RW, Bayer A, Inglis F, Barker A, Phul R. Safety and tolerability of once-daily versus twice-daily memantine: a randomised, doubleblind study in moderate to severe Alzheimer's disease. Int J Geriatr Psychiatry. 2007;22:258-262.

51. Waldemar G, Hyvarinen M, Josiassen MK, Korner A, Lehto H, Wetterberg P. Tolerability of switching from donepezil to memantine treatment in patients with moderate to severe Alzheimer's disease. Int J Geriatr Psychiatry. 2008;23:979-981.

52. Gauthier S, Loft H, Cummings J. Improvement in behavioural symptoms in patients with moderate to severe Alzheimer's disease by memantine: a pooled data analysis. Int J Geriatr Psychiatry. 2008;23:537-545.

53. Wilcock GK, Ballard CG, Cooper JA, Loft H. Memantine for agitation/ aggression and psychosis in moderately severe to severe Alzheimer's disease: a pooled analysis of 3 studies. J Clin Psychiatry. 2008;69: 341-348.

54. Maidment ID, Fox CG, Boustani M, Rodriguez J, Brown RC, Katona CL. Efficacy of memantine on behavioral and psychological symptoms related to dementia: a systematic meta-analysis. Ann Pharmacother. 2008;42:32-38.

55. Cummings JL, Mackell J, Kaufer D. Behavioral effects of current Alzheimer's disease treatments: a descriptive review. Alzheimers Dement 2008;4:49-60.

56. Grossberg GT, Pejovic V, Miller ML, Graham SM. Memantine therapy of behavioral symptoms in community-dwelling patients with moderate to severe Alzheimer's disease. Dement Geriatr Cogn Disord. 2009;27:164-172.

57. Peskind ER, Potkin SG, Pomara N, et al. Memantine treatment in mild to moderate Alzheimer disease: a 24-week randomized, controlled trial. Am J Geriatr Psychiatry. 2006;14:704-715.

58. Porsteinsson APGG, Mintzer J, Olin JT. Memantine treatment in patients with mild to moderate Alzheimer's disease already receiving a cholinesterase inhibitor: a randomized, double-blind, placebo-controlled trial. Curr Alzheimer Res. 2008;5:83-89.

59. Bakchine S, Loft H. Memantine treatment in patients with mild to moderate Alzheimer's disease: results of a randomised, doubleblind, placebo-controlled 6-month study. J Alzheimers Dis. 2007;11: 471-479.

60. Vidal JS, Lacombe JM, Dartigues JF, et al. Evaluation of the impact of memantine treatment initiation on psychotropics use: a study from the French national health care database. Neuroepidemiology. 2008;31:193-200.
61. Farlow MR, Cummings JL. Effective pharmacologic management of Alzheimer's disease. Am J Med. 2007;120:388-397.

62. Dantoine T, Auriacombe S, Sarazin M, Becker H, Pere JJ, Bourdeix I. Rivastigmine monotherapy and combination therapy with memantine in patients with moderately severe Alzheimer's disease who failed to benefit from previous cholinesterase inhibitor treatment. Int $\mathrm{J}$ Clin Pract. 2006;60:110-118.

63. Hsiung GY, Feldman HH. Pharmacological treatment in moderateto-severe Alzheimer's disease. Expert Opin Pharmacother. 2008;9: 2575-2582.

64. Stolee P, Rockwood K, Fox RA, Streiner DL. The use of goal attainment scaling in a geriatric care setting. J Am Geriatr Soc. 1992;40:574-578.

65. Rockwood K, Stolee P, Howard K, Mallery L. Use of Goal Attainment Scaling to measure treatment effects in an anti-dementia drug trial. Neuroepidemiology. 1996;15:330-338.

66. Jacova C, Schulzer M, Money J, et al. Cross-sectional validation of a new instrument for the measurement of treatment response: the Clinical Meaningfulness in Alzheimer Disease Treatment (CLIMAT) scale. Alzheimers Dement. 2009;5:184.

67. Jacova C, Schulzer M, Money J, et al. Social impact in the measurement of clinically meaningful change: Findings from the cross-sectional validation of the Clinical Meaningfulness in Alzheimer Disease Treatment (CLIMAT) scale. Alzheimers Dement. 2009;5:188.

68. Gagnon M, Rive B, Hux M, Guilhaume C. Cost-effectiveness of memantine compared with standard care in moderate-to-severe Alzheimer disease in Canada. Can J Psychiatry. 2007;52:519-526.

69. Antonanzas F, Rive B, Badenas JM, Gomez-Lus S, Guilhaume C. Cost-effectiveness of memantine in community-based Alzheimer's disease patients: An adaptation in Spain. Eur J Health Econ. 2006;7: 137-144.

70. Jones RW, McCrone P, Guilhaume C. Cost effectiveness of memantine in Alzheimer's disease: an analysis based on a probabilistic Markov model from a UK perspective. Drugs Aging. 2004;21:607-620.

71. Francois C, Sintonen H, Sulkava R, Rive B. Cost effectiveness of memantine in moderately severe to severe Alzheimer's disease: a markov model in Finland. Clin Drug Investig. 2004;24:373-384.

72. Jonsson L. Cost-effectiveness of memantine for moderate to severe Alzheimer's disease in Sweden. Am J Geriatr Pharmacother. 2005; 3:77-86.

73. Geldmacher DS. Cost-effectiveness of drug therapies for Alzheimer's disease: A brief review. Neuropsychiatr Dis Treat. 2008;4:549-555.
Neuropsychiatric Disease and Treatment

\section{Publish your work in this journal}

Neuropsychiatric Disease and Treatment is an international, peerreviewed journal of clinical therapeutics and pharmacology focusing on concise rapid reporting of clinical or pre-clinical studies on a range of neuropsychiatric and neurological disorders. This journal is indexed on PubMed Central, the 'PsycINFO' database and CAS, and is the official

\section{Dovepress}

journal of The International Neuropsychiatric Association (INA). The manuscript management system is completely online and includes a very quick and fair peer-review system, which is all easy to use. Visit http://www.dovepress.com/testimonials.php to read real quotes from published authors. 